\title{
Efficacy of Sand Filtration and Ultraviolet Irradiation as Seawater Treatment to Prevent Kudoa septempunctata (Myxozoa: Multivalvulida) Infection in Olive Flounder Paralichthys olivaceus
}

\author{
Toyohiro Nishioka ${ }^{1}$, Jun Satoh ${ }^{1}$, Tohru Mekata ${ }^{1}$, Koh-ichiro Mori ${ }^{2}$, Kengo Ohta ${ }^{3}$, Taizo Morioka ${ }^{4}$, \\ Meibi Lu $^{5}$, Hiroshi Yokoyama ${ }^{5 *}$ and Tomoyoshi Yoshinaga ${ }^{5}$ \\ ${ }^{1}$ Kamiura Laboratory, National Research Institute of Aquaculture, Oita 879-2602, Japan \\ ${ }^{2}$ National Research Institute of Aquaculture, Mie 516-0193, Japan \\ ${ }^{3}$ Hakatajima Laboratory, National Research Institute of Fisheries and Environment of Inland Sea, \\ Ehime 794-2305, Japan \\ ${ }^{4}$ Amami Laboratory, Research Center for Tuna Aquaculture, Seikai National Fisheries \\ Research Institute, Kagoshima 894-2414, Japan \\ ${ }^{5}$ Graduate School of Agricultural and Life Sciences, The University of Tokyo, \\ Tokyo 113-8657, Japan
}

(Received October 26, 2015)

\begin{abstract}
Kudoa septempunctata infecting the muscle of the olive flounder Paralichthys olivaceus has been recently demonstrated to cause food poisoning in humans who eat the raw flesh of flounder. In the present study, we assessed the effective treatments of a water supply to prevent $K$. septempunctata infection in a flounder hatchery where the parasite was enzootic. The prevalence of infection in a positive control fish group exposed to unfiltered seawater was $33 \%$ at 3 months post-exposure, whereas no infection was observed in the treated fish groups exposed to sand-filtered seawater, sand- and cartridge ( $5 \mu \mathrm{m}$ )-filtered seawater or sand-filtered seawater followed by ultraviolet (UV) irradiation at a dose of $46 \mathrm{~mJ} / \mathrm{cm}^{2}$. Additionally, treatment with UV irradiation alone was effective for the prevention of $K$. septempunctata infection. To ensure complete protection from $K$. septempunctata infection, we recommend double treatments of a water supply with sand filtration and UV irradiation in olive flounder hatcheries.
\end{abstract}

Key words: Kudoa septempunctata, Paralichthys olivaceus, olive flounder, food poisoning, ultraviolet irradiation, sand filtration

Myxosporeans belonging to the genus Kudoa are parasites that decrease the commercial value of the host fish because of either post-mortem myoliquefaction or macroscopic cysts in the trunk muscle (Moran et al., 1999a; Eiras et al., 2014). Moreover, K. septempunctata infecting the muscle of the olive flounder Paralichthys olivaceus has recently been demonstrated as a causative agent of food poisoning in humans (Kawai et al., 2012; Sugita-Konishi et al., 2014). After ingestion of the raw flesh of infected flounder, patients showed acute diarrhea and vomiting within $2-20 \mathrm{~h}$.

To prevent food poisoning caused by $K$. septempunctata, heating or freezing of infected flounder flesh at $95^{\circ} \mathrm{C}$ for $10 \mathrm{~min}$ or at $-80^{\circ} \mathrm{C}$ overnight,

\footnotetext{
* Corresponding author

E-mail: ayokoh@mail.ecc.u-tokyo.ac.jp
}

respectively, is effective (Sugita-Konishi et al., 2014). However, such treatments are impractical because of the Japanese preference for raw fish flesh (Yokoyama, 2013; Yokoyama et al., 2015). To remove infected fish from fish farms, application of PCR assays based on Grabner et al. (2012) (or a modified protocol) and microscopic examination of muscle tissue were recommended by the Fisheries Agency of the Ministry of Agriculture, Forestry, and Fisheries of Japan (webpage of the Fisheries Agency, Japan: http://www.jfa.maff.go. jp/test/saibai/pdf/kudoa2.pdf, "accessed 1 October 2015”).

Our previous study demonstrated that $K$. septempunctata infection occurred predominantly during the rearing period of juveniles in olive flounder hatcheries, and we hypothesized that the infectious stage of $K$. septempunctata could be eliminated by sand-filtration and/or ultraviolet (UV) irradiation (Yokoyama et al., 2015). 
Disinfection of rearing water by UV irradiation has been successfully used for prevention of infectious diseases in aquaculture farms (Kasai et al., 2002; Yoshimizu, 2009). The efficacy of UV irradiation has also been reported for $K$. neurophila, $K$. amamiensis and K. yasunagai (Cobcroft and Battaglene, 2013; Shirakashi et al., 2014).

Thus, we aimed to develop effective control measures using mechanical filtration and UV treatment of the water supply in a hatchery where $K$. septempunctata infection was enzootic.

\section{Materials and Methods}

Fish and rearing facility

As experimental fish, olive flounder juveniles (approximately $5 \mathrm{~cm}$ in body length) were transported from a private hatchery (Marinetech Co. Ltd.) where there was no history of $K$. septempunctata infection, to a hatchery where the parasite was enzootic. They were reared in 1-kL (for Experiment 1) or 150-L (for Experiment 2 and 3) circular tanks. For Experiment 4, experimental fish were produced at the infected hatchery with a water supply treated by mechanical filtration and UV irradiation. Tanks were supplied with flowthrough seawater at a flow-rate of $500 \mathrm{~L} / \mathrm{h}$. The fish were fed daily with a commercial pellet diet (Otohime EP1, Nisshin Marubeni). At the start of the experiment, 30 fish were examined to confirm that they were negative for infection with $K$. septempunctata by PCR assay described in the following paragraph.

\section{Parasite examination}

$K$. septempunctata infection was examined by light microscopy and/or PCR assay according to the modified protocol of Grabner et al. (2012). The muscle tissues were removed from the flounder's eyed-side dorsal trunk or the tail. For light microscopy, a wet mount preparation of roughly $20 \mathrm{mg}$ of muscle tissue was made on a glass slide, and the presence or absence of spores was observed under a light microscope (CX41, Olympus). For the PCR assay, DNA was extracted from approximately $25 \mathrm{mg}$ of the fish tissues using a QIAamp ${ }^{\circledR}$ DNA Mini Kit (Qiagen) following the manufacturer's protocol. To amplify the $K$. septempunctata $28 \mathrm{~S}$ rDNA, the primer pairs KSf (5'-GTG TGT GAT CAG ACT TGA TAT G-3') and KSr (5'-AAG CCA AAA CTG CTG GCC ATT T-3') were used. PCR reactions were performed in a $20-\mu \mathrm{L}$ total volume mixture. Each PCR mixture contained $0.1 \mu \mathrm{L}$ of Ex Taq HS (Takara), $2 \mu \mathrm{L}$ of $10 \times$ Ex Taq Buffer, $1.6 \mu \mathrm{L}$ of dNTP mixture (2.5 mM of each), $0.4 \mu \mathrm{L}$ of each primer, and $1.0 \mu \mathrm{L}$ of extracted DNA suspension. All PCR reactions were performed in an iCycler (Bio-Rad). Denaturation of DNA $\left(95^{\circ} \mathrm{C}\right.$ for $\left.4 \mathrm{~min}\right)$ was followed by 35 cycles of amplification consisting of $30 \mathrm{~s}$ for denaturation at $95^{\circ} \mathrm{C}$,
$30 \mathrm{~s}$ for annealing at $53^{\circ} \mathrm{C}$, and $30 \mathrm{~s}$ for extension at $72^{\circ} \mathrm{C}$, ending with a 5 min extension at $72^{\circ} \mathrm{C}$. PCR products were analyzed by $1.5 \%$ agarose gel electrophoresis with TAE (40 mm Tris-acetate, $1 \mathrm{~mm}$ EDTA) running buffer.

\section{Experiment 1 (Mechanical filtration combined with UV irradiation)}

Fish were divided into four $1-\mathrm{kL}$ circular tanks (each 200 fish) situated in an indoor facility of the hatchery. Fish of the positive control group were exposed, for three months from September to December 2012 , to unfiltered seawater, whereas fish of the treated groups were exposed to 1) sand-filtered (specified capture particle size > $10 \mu \mathrm{m}$ ) seawater, 2) sand- and cartridge-filtered (5 $\mu \mathrm{m}$ after pre-filtration of $150 \mu \mathrm{m}$ ) seawater, or 3) sand-filtered seawater followed by UV irradiation at a dose of $46 \mathrm{~mJ} / \mathrm{cm}^{2}$ (PW10-ES-P755, Ebara Jitsugyo Co. Ltd.). Additionally, as a negative control, approximately 200 fish from the same stock were reared in the Kamiura Laboratory, National Research Institute of Aquaculture (NRIA), Oita Prefecture, where $K$. septempunctata had never been detected. At NRIA, fish were reared in a 3-kL tank supplied with seawater treated with an electrolyzer (ESF-050, Ebara Jitsugyo Co. Ltd.) and subsequently dechlorinated by activated carbon. During the 3-month experimental period, twenty fish were collected from all groups at 1 and 2 months p.e. At the end of the experiment (3 months p.e.), thirty fish were collected from each group. Sampled fish were subjected to the microscopic observation and PCR assay described above. In addition to the muscle tissue, blood was also analyzed by PCR. Statistical analyses were performed to compare the prevalence of infection between untreated and treated groups at the corresponding point of time using Fisher's exact probability test (one tail test, $p<0.01$ ).

\section{Experiment 2 (Sand filtration or UV irradiation)}

Fish were divided into three 150-L circular tanks (each 75 fish) and reared for two weeks at the hatchery. Fish of the positive control group were exposed to unfiltered seawater for two weeks, whereas fish of the treated groups were exposed to 1) sand-filtered seawater or 2) UV (46 mJ/cm², PW10-ES-P755, Ebara Jitsugyo Co. Ltd.) irradiated unfiltered seawater. Subsequently, fish were moved to an indoor facility at NRIA (Kamiura Laboratory) and were kept in the same conditions as in the negative control in Experiment 1 for three months. During the rearing period at NRIA, ten fish were sampled at 1 and 2 months p.e., and then thirty fish were collected at 3 months p.e. Fish were examined for $K$. septempunctata infection in the trunk muscle by PCR. The experiment, with equivalent conditions, was repeated three times in July, August, and September 2013. Statistical analyses were performed to compare 
the prevalence of infection between untreated and treated groups at the corresponding point of time using Fisher's exact probability test (one tail test, $p<0.01$ ).

\section{Experiment 3 (Dose of UV irradiation)}

Fish were distributed into four 150-L tanks (each 60 fish), which were exposed to unfiltered seawater (a positive control), or unfiltered seawater treated with UV doses of 11, 23 and $46 \mathrm{~mJ} / \mathrm{cm}^{2}$ (PW10-ES-P751, PW10ES-P753, PW10-ES-P755, respectively, Ebara Jitsugyo, Co. Ltd.) at the hatchery for two weeks in July 2014. Thereafter, fish were transferred to NRIA (Kamiura Laboratory) and kept in the same conditions as in the negative control in Experiments 1 and 2 for 3 months. During the rearing period at NRIA, ten fish were sampled at 1 and 2 months p.e., and thirty fish were collected at 3 months p.e. Fish were examined for $K$. septempunctata infection in the trunk muscle by PCR. Statistical analyses were performed to compare the prevalence of infection between untreated and treated groups at the corresponding point of time using Fisher's exact probability test (one tail test, $p<0.01$ ).

\section{Experiment 4 (Verification test of sand-filtration com- bined with UV irradiation)}

Experimental fish were produced at the hatchery with a water supply treated by mechanical filtration and UV irradiation, followed by distribution into two 1-kL tanks (each approximately 800 fish) at the hatchery in July 2014. One group (a positive control) was exposed to unfiltered seawater, and the other group was exposed to sand-filtered and UV-irradiated $\left(46 \mathrm{~mJ} / \mathrm{cm}^{2}\right.$, PW10-ES-P755, Ebara Jitsugyo Co. Ltd.) seawater. After rearing for 1 month, the fish were moved to NRIA and were kept until October 2014. Thirty fish were sampled from each groups at 1,2 , and 3 months p.e. for parasite examinations. The prevalence of infection with $K$. septempunctata was determined by the PCR assay. Statistical analyses were performed to compare the prevalence of infection between untreated and treated groups at the corresponding point of time using Fisher's exact probability test (one tail test, $p<0.01$ ).

\section{Results}

Experiment 1 (Mechanical filtration and UV irradiation)

Only the positive control group had moderate infections (5-33\%) with $K$. septempunctata in the muscle during the 3-month experimental period (Table 1). Blood infection was found only at 1 month p.e. in the positive control. None of the 210 fish that were exposed to the treated seawater exhibited $K$. septempunctata infection in the muscle and the blood. In addition, 30 unexposed, untreated control fish were also negative.

\section{Experiment 2 (Sand filtration or UV irradiation)}

Three trials conducted in 3 different months provided similar results, demonstrating the efficacy of these water treatments in eliminating the infectivity of $K$. septempunctata from seawater; no infection was detected from fish exposed to UV-treated or sand-filtrated seawater (Table 2). At 3 months p.e., the prevalence of infection in the positive control was higher in July (37\%) than in August and September (10\% and $3.3 \%$, respectively). A significant difference between the positive control and the treated groups was found only at 3 months p.e. in the experiment conducted in July.

\section{Experiment 3 (Dose of UV irradiation)}

The positive control fish had relatively light infection

Table 1. Prevalence of infection with Kudoa septempunctata in olive flounder exposed to untreated or treated seawater (SW) in 2012 (Experiment 1)

\begin{tabular}{|c|c|c|c|c|c|}
\hline \multirow{2}{*}{ Experiment } & \multirow{2}{*}{$\begin{array}{c}\text { Examination } \\
\text { site }\end{array}$} & \multirow{2}{*}{$\begin{array}{l}\text { Examination } \\
\text { method }\end{array}$} & \multicolumn{3}{|c|}{ Months p.e. } \\
\hline & & & 1 & 2 & 3 \\
\hline \multirow{3}{*}{$\begin{array}{l}\text { Positive control } \\
\text { (unfiltered SW) }\end{array}$} & \multirow{2}{*}{ Muscle } & PCR & $1 / 20$ & $3 / 20$ & $10 / 30$ \\
\hline & & Microscopy & $0 / 20$ & $3 / 20$ & $3 / 30$ \\
\hline & Blood & PCR & $14 / 20$ & $0 / 20$ & $0 / 30$ \\
\hline \multirow{3}{*}{ Sand-filtered SW } & \multirow{2}{*}{ Muscle } & PCR & $0 / 20$ & $0 / 20$ & $0 / 30 *$ \\
\hline & & Microscopy & $0 / 20$ & $0 / 20$ & $0 / 30$ \\
\hline & Blood & PCR & $0 / 20 *$ & $0 / 20$ & $0 / 30$ \\
\hline \multirow{3}{*}{$\begin{array}{l}\text { Sand-filtered and } \\
\text { cartridge-filtered SW }\end{array}$} & \multirow{2}{*}{ Muscle } & PCR & $0 / 20$ & $0 / 20$ & $0 / 30 *$ \\
\hline & & Microscopy & $0 / 20$ & $0 / 20$ & $0 / 30$ \\
\hline & Blood & PCR & $0 / 20 *$ & $0 / 20$ & $0 / 30$ \\
\hline \multirow{3}{*}{$\begin{array}{l}\text { Sand-filtered and } \\
\text { UV-treated SW }\end{array}$} & \multirow{2}{*}{ Muscle } & PCR & $0 / 20$ & $0 / 20$ & $0 / 30 *$ \\
\hline & & Microscopy & $0 / 20$ & $0 / 20$ & $0 / 30$ \\
\hline & Blood & PCR & $0 / 20^{*}$ & $0 / 20$ & $0 / 30$ \\
\hline
\end{tabular}

Data represent the numbers of positive fish/numbers of examined fish.

* Significantly different from the positive control (Fisher's exact probability test, one tail test, $p<0.01$ ). 
Table 2. Prevalence of infection with Kudoa septempunctata in the muscle of olive flounder exposed to untreated or treated seawater (SW) in 2013 (Experiment 2)

\begin{tabular}{|c|c|c|c|c|}
\hline \multirow{2}{*}{$\begin{array}{l}\text { Month of } \\
\text { exposure }\end{array}$} & \multirow{2}{*}{ Experiment } & \multicolumn{3}{|c|}{ Months p.e. } \\
\hline & & 1 & 2 & 3 \\
\hline \multirow{3}{*}{ July } & $\begin{array}{l}\text { Positive control } \\
\text { (unfiltered SW) }\end{array}$ & $2 / 10$ & $2 / 10$ & $11 / 30$ \\
\hline & Sand-filtered SW & $0 / 10$ & $0 / 10$ & $0 / 30 *$ \\
\hline & UV-treated SW & $0 / 10$ & $0 / 10$ & $0 / 30 *$ \\
\hline \multirow{3}{*}{ August } & $\begin{array}{l}\text { Positive control } \\
\text { (unfiltered SW) }\end{array}$ & $1 / 10$ & $1 / 10$ & $3 / 30$ \\
\hline & Sand-filtered SW & $0 / 10$ & $0 / 10$ & $0 / 30$ \\
\hline & UV-treated SW & $0 / 10$ & $0 / 10$ & $0 / 30$ \\
\hline \multirow{3}{*}{ September } & $\begin{array}{l}\text { Positive control } \\
\text { (unfiltered SW) }\end{array}$ & $0 / 10$ & $1 / 10$ & $1 / 30$ \\
\hline & Sand-filtered SW & $0 / 10$ & $0 / 10$ & $0 / 30$ \\
\hline & UV-treated SW & $0 / 10$ & $0 / 10$ & $0 / 30$ \\
\hline
\end{tabular}

Data represent the numbers of PCR-positive fish/numbers of examined fish.

*Significantly different from the positive control (Fisher's exact probability test, one tail test, $p<0.01$ ).

Table 3. Prevalence of infection with Kudoa septempunctata in the muscle of olive flounder exposed to ultraviolet (UV) treated seawater (SW) in 2014 (Experiment 3)

\begin{tabular}{ccccc}
\hline \multirow{2}{*}{ Experiment } & $\begin{array}{c}\text { Dose of UV } \\
\left(\mathrm{mJ} / \mathrm{cm}^{2}\right)\end{array}$ & \multicolumn{4}{c}{ Months p.e. } \\
\cline { 3 - 5 } & & 1 & 2 & 3 \\
\hline Positive control & 0 & $1 / 10$ & $2 / 10$ & $3 / 30$ \\
(untreated SW) & & $0 / 10$ & $0 / 10$ & $0 / 30$ \\
Low dose UV & 11 & $0 / 10$ & $0 / 10$ & $0 / 30$ \\
Medium dose UV & 23 & $0 / 10$ & $0 / 10$ & $0 / 30$ \\
High dose UV & 46 &
\end{tabular}

Data represent the numbers of PCR-positive fish/numbers of examined fish.

Table 4. Prevalence of infection with Kudoa septempunctata in the muscle of olive flounder exposed to untreated or treated seawater (SW) in a verification test of sand-filtration combined with UV irradiation in 2014 (Experiment 4)

\begin{tabular}{cccc}
\hline \multirow{2}{*}{ Experiment } & \multicolumn{3}{c}{ Months p.e. } \\
\cline { 2 - 4 } & 1 & 2 & 3 \\
\hline $\begin{array}{c}\text { Positive control (unfiltered SW) } \\
\text { Sand-filtered and UV-treated } \\
\left(46 \mathrm{~mJ} / \mathrm{cm}^{2}\right) \text { SW }\end{array}$ & $7 / 30$ & $16 / 30$ & $13 / 30$ \\
& $0 / 30$ & $0 / 30^{*}$ & $0 / 30^{*}$ \\
\hline
\end{tabular}

Data represent the numbers of PCR-positive fish/numbers of examined fish.

*Significantly different from the positive control (Fisher's exact probability test, one tail test, $p<0.01$ ).

with K. septempunctata (10-20\%) during the 3-month experimental period, whereas all UV-treated groups were negative for infection (Table 3). However, there was no significant difference between the positive control and UV-treated groups at the corresponding point of time due to the low prevalence of infection.
Experiment 4 (Verification test of sand-filtration combined with UV irradiation)

The positive control fish were infected (23-53\%), but the experimental fish reared in seawater treated by sand-filtration and UV irradiation were negative for infection (zero out of 90 fish examined).

\section{Discussion}

The present study indicates that seawater treatment with sand-filtration or UV irradiation is effective in preventing Kudoa septempunctata infection in juvenile olive flounder. However, the failure of mechanical filtration, including sand-, cartridge- and fiber-filtration, and foam fractionation for trapping several species of Kudoa in seawater has been documented (Moran et al., 1999b; Cobcroft and Battaglene, 2013; Shirakashi et al., 2014). Moran et al. (1999b) reported that the infective stage of $K$. thyrsites was able to pass through the sand-, bag- or cartridge $(<1 \mu \mathrm{m})$-filters. The authors suggested that the results do not indicate that the infective stage is smaller than $1 \mu \mathrm{m}$ but that the filters are inefficient at removing all microscopic organisms and particles. The success of the present study may be explained by a larger size of actinospores than those of other Kudoa species, although the actinospore stage of $K$. septempunctata has not yet been identified. Alternatively, the efficacy might be attributed to the gravity sand-filtration system used in the present study because pressure sand-filtration was ineffective for preventing K. amamiensis infection (Shirakashi et al., 2014). Nevertheless, mechanical treatment could be affected by various conditions, such as cleanliness of the filtration materials, often resulting in unreliable results. Likewise, the sterilizing efficiency of UV irradiation depends on water transparency. Therefore, we propose a treatment system with mechanical filtration to remove suspended particles before UV irradiation to ensure complete protection from $K$. septempunctata infection.

In Experiment 2, treatments significantly inactivated $K$. septempunctata infection in the trial conducted in July only. However, the absence of significant differences in the experiments conducted in August and September may be attributable to the low prevalence of infection in the periods. As shown in the previous study (Yokoyama et al., 2015), it is possible that the amount of the infective stage of $K$. septempunctata in seawater decreased after the peak period of infection (July). The results of the present study showed that the infection continued until at least September, even though it was only a light infection, which indicates the need of prolonged seawater treatment during the rearing period to completely eliminate $K$. septempunctata infection.

Considering the operational costs, it is important to 
determine the minimum UV dose required for prevention of Kudoa infection. Cobcroft and Battaglene (2013) reported that a dose of $>44 \mathrm{~mJ} / \mathrm{cm}^{2}$ was effective in preventing $K$. neurophila infection. Shirakashi et al. (2014) indicated that UV treatments with doses of 68 and $216 \mathrm{~mJ} / \mathrm{cm}^{2}$ prevented the infection of $K$. yasunagai and $K$. amamiensis, respectively. In the present study (Experiment 3), UV irradiations at doses ranging from 11 to $46 \mathrm{~mJ} / \mathrm{cm}^{2}$ provided complete protection from $\mathrm{K}$. septempunctata infection, but the results were not significantly different from the positive control due to the low prevalence of infection. This may be likely caused by a smaller amount of actinospores in 2014 compared with previous years. Seasonal variation in parasite density in seawater has been reported (Alama-Bermejo et al., 2013; Ishimaru et al., 2014). A longer exposure period might have compensated for the smaller amount of parasite. Further studies are required to determine the minimal UV dose.

We recommend a dual use of sand-filtration and UV irradiation at $>46 \mathrm{~mJ} / \mathrm{cm}^{2}$ as seawater treatment to prevent $K$. septempunctata infection in flounder hatcheries. The successful result in the verification test (Experiment 4) demonstrates the feasibility of this water treatment procedure, even at the commerciallevel needed for hatchery water supplies, to protect juvenile olive flounder from infection with $K$. septempunctata. Indeed, non-infected juvenile flounder stock ( $\mathrm{n}=$ 300,000 to $400,000,7-12 \mathrm{~cm}$ in total length) was produced in the hatchery in 2014, when the seawater treatment of sand-filtration and UV irradiation was applied to practice. Larvae were hatched from eggs collected from broodstock held in the hatchery in March 2014 and were subsequently reared in a $20-\mathrm{kL}$ tank supplied with sand-, fiber- (Marimo), and cartridge-filtered seawater, followed by UV irradiation at a dose of $46 \mathrm{~mJ} / \mathrm{cm}^{2}$ (PO$10 \mathrm{MN}$, Seabass Limited). This juvenile fish stock was confirmed to be negative for $K$. septempunctata infection by PCR analysis.

\section{Acknowledgments}

We gratefully acknowledge the olive flounder hatchery for their cooperation. We thank Dr. Sho Shirakashi of Kinki University for his help with the fieldwork. We are grateful to Naoko Funaguma for her technical assistance with the molecular work. This research was partly supported by a grant from the Ministry of Agriculture, Forestry, and Fisheries of Japan (Regulatory Research Projects for Food Safety, Animal Health and Plant Protection, No. 2403).

\section{References}

Alama-Bermejo, G., R. Šíma, J. A. Raga and A. S. Holzer (2013): Understanding myxozoan infection dynamics in the sea: seasonality and transmission of Ceratomyxa puntazzi. Int. J. Parasitol., 43, 771-780.

Cobcroft, J. M. and S. C. Battaglene (2013): Ultraviolet irradiation is an effective alternative to ozonation as a sea water treatment to prevent Kudoa neurophila (Myxozoa: Myxosporea) infection of striped trumpeter, Latris lineata (Forster). J. Fish Dis., 36, 57-65.

Eiras, J. C., A. Saraiva and C. Cruz (2014): Synopsis of the species of Kudoa Meglitsch, 1947 (Myxozoa: Myxosporea: Multivalvulida). Syst. Parasitol., 87, 153-180.

Grabner, D. S., H. Yokoyama, S. Shirakashi and R. Kinami (2012): Diagnostic PCR assays to detect and differentiate Kudoa septempunctata, $K$. thyrsites and K. lateolabracis (Myxozoa, Multivalvulida) in muscle tissue of olive flounder (Paralichthys olivaceus). Aquaculture, 338-341, 36-40.

Ishimaru, K., T. Matsuura, K. Tsunemoto and S. Shirakashi (2014): Seasonal monitoring of Kudoa yasunagai from sea water and aquaculture water using quantitative PCR. Dis. Aquat. Organ., 108, 45-52.

Kasai, H., S. Osawa, T. Kobayashi and M. Yoshimizu (2002): Prevention of scuticociliatosis in Japanese flounder by treatment of water-supply with a high quality UV lamp. Fish Pathol., 37, 199-200.

Kawai, T., T. Sekizuka, Y. Yahata, M. Kuroda, Y. Kumeda, Y. lijima, Y. Kamata, Y. Sugita-Konishi and T. Ohnishi (2012): Identification of Kudoa septempunctata as the causative agent of novel food poisoning outbreaks in Japan by consumption of Paralichthys olivaceus in raw fish. Clin. Infect. Dis., 54, 1046-1052.

Moran, J. D. W., D. J. Whitaker and M. L. Kent (1999a): A review of the myxosporean genus Kudoa Meglitsch, 1947, and its impact on the international aquaculture industry and commercial fisheries. Aquaculture, 172, 163-196.

Moran, J. D. W., D. J. Whitaker and M. L. Kent (1999b): Natural and laboratory transmission of the marine myxozoan parasite Kudoa thyrsites to Atlantic salmon. J. Aquat. Anim. Health, 11, 110-115.

Shirakashi, S., T. Nishimura, N. Kameshima, H. Yamashita, H. Ishitani, K. Ishimaru and H. Yokoyama (2014): Effectiveness of ultraviolet irradiation of seawater for the prevention of Kudoa yasunagai and Kudoa amamiensis (Myxozoa: Multivalvulida) infections in Seriola fish. Fish Pathol., 49, 141-144.

Sugita-Konishi, Y., H. Sato and T. Ohnishi (2014): Novel foodborne disease associated with consumption of raw fish, olive flounder (Paralichthys olivaceus). Food Safety, 2, $141-150$.

Yokoyama, H. (2013): Parasitosis caused by ingestion of raw fish. Jpn. J. Food Microbiol., 30, 100-103. (In Japanese)

Yokoyama, H., M. Lu, K. Mori, J. Satoh, T. Mekata and T. Yoshinaga (2015): Infection dynamics of Kudoa septempunctata (Myxozoa: Multivalvulida) in hatchery-produced olive flounder Paralichthys olivaceus. Fish Pathol., 50, 60-67.

Yoshimizu, M. (2009): Control strategy for viral diseases of salmonid fish, flounders and shrimp at hatchery and seed production facility in Japan. Fish Pathol., 44, 9-13. 